\title{
Erratum to: Zooplankton-phytoplankton relationships in shallow subtropical versus temperate lakes Apopka (Florida, USA) and Trasimeno (Umbria, Italy)
}

\author{
Karl E. Havens • Antonia Concetta Elia • \\ Maria Illuminata Taticchi $\cdot$ Rolland S. Fulton III
}

Published online: 30 November 2010

(C) Springer Science+Business Media B.V. 2010

\section{Erratum to: Hydrobiologia \\ DOI 10.1007/s10750-009-9754-4}

In this article, a systematic error in converting phytoplankton biovolume to carbon biomass resulted in 2.5-fold over-estimates of phytoplankton biomass (BP) for all data presented in the paper. These errors do not affect any of the conclusions; however, they do result in BP data being incorrectly scaled in five figures, which are presented below in their corrected form. The only notable change is that in Fig. 7, where the two study lakes are presented in comparison with their Florida and European counterparts, the datum for Lago Trasimeno now groups tightly with other European lakes having a similar BP and zooplankton biomass (BZ). Lake Apopka remains an extreme outlier in regard to a much lower BZ than expected based on BP.
The online version of the original article can be found under doi:10.1007/s10750-009-9754-4.

K. E. Havens $(\square)$

Florida Sea Grant College Program, University of Florida,

Building 803 McCarty Drive, Gainesville,

FL 32611-0400, USA

e-mail: khavens@ufl.edu

A. C. Elia - M. I. Taticchi

University of Perugia, Perugia, Italy

R. S. Fulton III

St. Johns River Water Management District, Palatka, FL, USA 

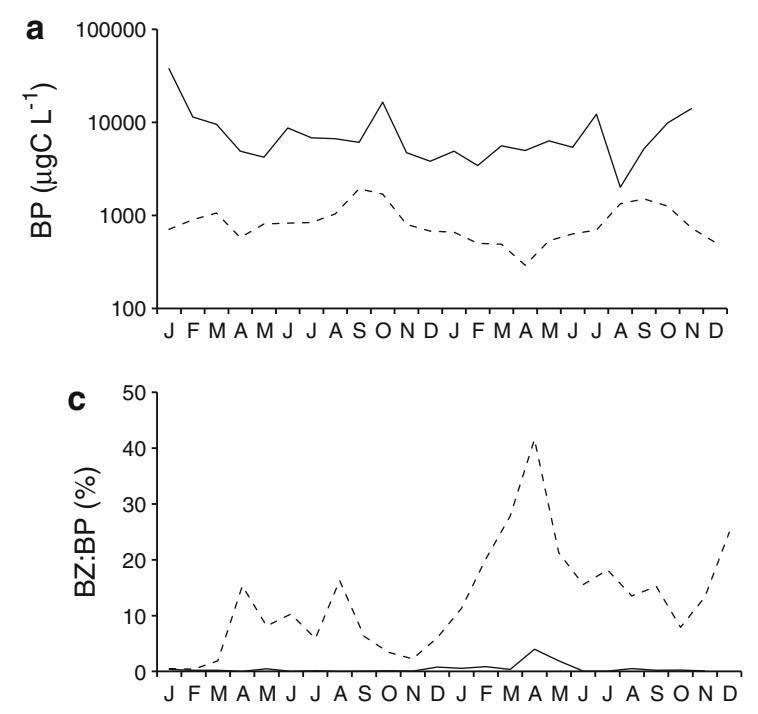

Fig. 2 a Biomass of phytoplankton at monthly intervals in the two lakes. The upper solid line is Lake Apopka and the lower dashed line is Lago Trasimeno. c Ratio of zooplankton to phytoplankton biomass in the two lakes. The upper dashed line is Lago Trasimeno and the lower solid line is Lake Apopka



Fig. 5 c Relationship between Secchi disk transparency and phytoplankton biomass (BP). Open circles are Lago Trasimeno data and solid squares are Lake Apopka data. The line is a log$\log$ regression, fitted to the data with the equation provided

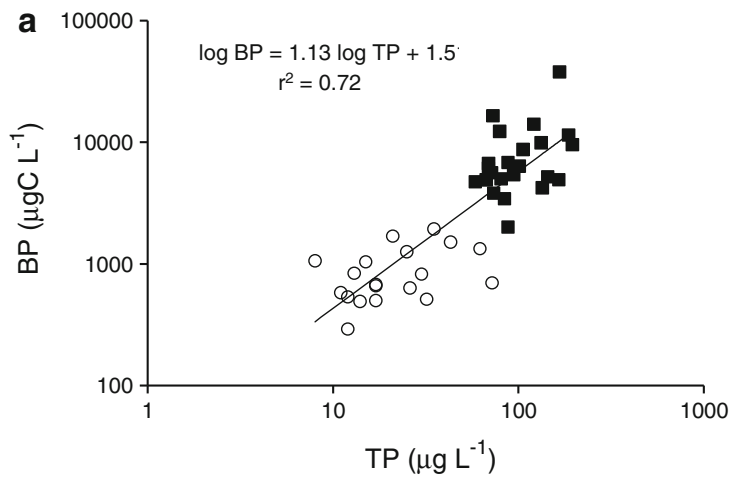

Fig. 6 a Relationship between phytoplankton biomass (BP) and total phosphorus (TP). Open circles are Lago Trasimeno data and solid squares are Lake Apopka data. The line is a log$\log$ regression, fitted to the data with the equation provided

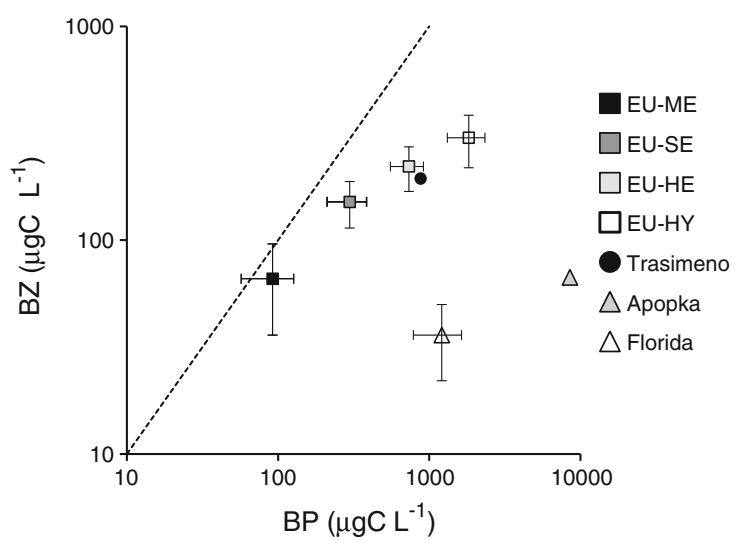

Fig. 7 Relationship between zooplankton biomass (BZ) and phytoplankton biomass (BP) in the two study lakes, in comparison with data from lakes in Florida and Europe (EU-ME European mesotrophic, EU-SE European slightly eutrophic, EU-HE European highly eutrophic, EU-HY European hypereutrophic). The dashed line is a 1:1 relationship 